\title{
Inter-Group Conflict and Intra-Group Punishment in an Experimental Contest Game
}

\author{
Klaus ABBInK*, JoRdi BRANDTS**, BENEDIKT HERRMANN*** AND HENRIK ORZEN*** \\ * CREED, University of Amsterdam \\ ** Institut d'Anàlisi Econòmica (CSIC), Barcelona \\ *** University of Nottingham
}

December 2007

\begin{abstract}
We study how conflict in a contest game is influenced by rival parties being groups and by group members being able to punish each other. Our main motivation stems from the analysis of socio-political conflict. The relevant theoretical prediction in our setting is that conflict expenditures are independent of group size and independent of whether punishment is available or not. We find, first, that our results contradict the independence of groupsize prediction: conflict expenditures of groups are substantially larger than those of individuals, and both are substantially above equilibrium. Towards the end of the experiment material losses in groups are $257 \%$ of the predicted level. There is, however, substantial heterogeneity in the investment behaviour of individual group members. Second, allowing group members to punish each other after individual contributions to the contest effort are revealed leads to even larger conflict expenditures. Now material losses are $869 \%$ of the equilibrium level and there is much less heterogeneity in individual group members' investments. These results contrast strongly with those from public goods experiments where punishment enhances efficiency and leads to higher material payoffs.
\end{abstract}

\section{Keywords}

Laboratory experiments, Rent-seeking, Conflict, Group competitiveness

\section{JEL Classification Codes}

C90, D72, D74, F51, H41

\section{Acknowledgements}

Financial support from the Leverhulme Trust under grant ECF/2003/0352 is gratefully acknowledged. 


\section{Author Addresses}

\section{Klaus Abbink}

\section{CREED}

Faculty of Economics and Econometrics

University of Amsterdam

Roetersstraat 11

1018WB Amsterdam

The Netherlands

fax: $\quad+31205255283$

phone: +31205254229

k.abbink@uva.nl

\section{Jordi Brandts}

Institut d'Anàlisi Econòmica (CSIC)

Campus UAB

08193 Bellaterra

Spain

fax $\quad+34935801452$

phone +34935806612

jordi.brandts@uab.es

\section{Benedikt Herrmann}

School of Economics

The University of Nottingham

University Park

Nottingham NG7 2RD

United Kingdom

fax: $\quad+441159514768$

phone: +441158466714

benedikt.herrmann@,nottingham.ac.uk

\section{Henrik Orzen}

School of Economics

The University of Nottingham

University Park

Nottingham NG7 2RD

United Kingdom

fax: $\quad+441159514768$

phone: +441158467847

henrik.orzen@nottingham.ac.uk 


\section{Introduction}

In many areas of social life different parties interact under conditions of rivalry, striving for something that not all can obtain. Examples of such rivalries in the economic and political realms are R\&D competition, promotion tournaments in internal labour markets, lobbying for government favours and electoral competition between political parties. As a result of such rivalries considerable resources are spent on activities that have no direct productive value.

For example, Hazlett and Michaels (1993) estimated that, previous to the adoption of auctions by the FCC, the real resources spent on filing applications for cell phone license lotteries (with an estimated market value of one billion dollars at that time) was about 400 million dollars. More extreme instances of rivalry are military conflicts and socio-political conflicts, like those that arise between parts of a country, when one of them is fighting for a different political status or independence, and those between ethnic groups. Actual conflicts of this type are often very costly, both in human lives and in material losses. To give just one recent example of human losses, Robinson (1995) reports that East Timor's conflict for independence has yielded a death toll of over 210,000 in a 25-year civil war with Indonesia. With respect to material losses, Abadie and Gardeazabal (2003) estimate that the political instability arising from the Basque conflict has led to a decline in per capita GDP of about 10 percentage points. Guidolin and La Ferrara (2005) study 112 conflicts during the period 19742004 and find that a sizeable fraction of them had a significant impact on major stock market and commodity prices. Fuentes (2005) reports estimates of the accumulated costs of violent conflict in Colombia, El Salvador and Guatemala equivalent to above 100\% of annual GDP.

Much of the economic analysis of conflict has been based on contest or rent-seeking models. Garfinkel and Skaperdas (2006) present an overview of the economics of conflict and Konrad (2007) provides a recent survey of the theoretical literature on contest models. In a contest several rival parties expend resources in trying to secure a prize or rent for themselves. In models of socio-political conflict, winning the prize represents the implementation of the political solution more favourable to the winning party. A contest success function based on the set of the players' (non-refundable) investments determines which contestant receives the prize. One of the most used contest models is the lottery game by Tullock $(1967,1980)$ in which each contesting party has a probability of winning the prize equal to the proportion of its investment out of the total investment by all parties. For players that maximise own material earnings this game has a unique Nash equilibrium in pure strategies. In the equilibrium, contestants invest positive amounts in a fight for the prize. This is socially wasteful in the sense that, as a consequence of spending material resources on an inherently unproductive activity, a certain fraction of the original prize is lost or dissipated.

A number of experimental studies like the ones of Isaac and Reynolds (1988), Millner and Pratt (1989, 1991), Shogren and Baik (1991), Davis and Reilly (1998), Potters, de Vries and van Winden (1998), Öncüler and Croson (2005) and Parco, Rapoport and Amaldoss (2005) 
have studied the lottery contest game and some related contest games. The central question these studies focus on is whether observed behaviour is consistent with standard Nash equilibrium predictions. It is mostly found that the expenditures on conflict activities exceed the relevant theoretical prediction (Öncüler and Croson provide a brief review). Deviations from equilibrium can have more than one explanation. Obstacles to convergence to equilibrium may be relevant. Another factor can be the interdependence of preferences. In other areas, like the analysis of public goods situations - see Andreoni and Miller (2002) - or that of gift-exchange labour markets - see Fehr et al. $(1993,1998)$ - it has been shown that elements of altruism, aversion to inequality and reciprocity have a strong influence on behaviour. In contest games such motivational forces may also have an influence. In particular, given the rivalry between the parties in conflict, the desires to come out ahead or to hurt others as well as other types of competitive motivational forces may affect behaviour (Herrmann and Orzen, 2007).

In all rent-seeking experiments mentioned above it is individuals who compete for a prize. In many naturally occurring situations, however, players are groups, since political parties, social movements, and associations like trade unions, lobbyists, terrorist groups etc. are invariably composed of more than one individual. Rent-seeking competition between groups rather than single players introduces an additional layer of complexity to the strategic characteristics of the interaction. Although groups clearly have the potential to be more powerful competitors than individual agents, they face internal coordination problems that may severely undermine their efficacy. For example, wage increases eked out by striking workers typically benefit both striking and non-striking workers, such that individual workers have an incentive not to participate in the strike and nevertheless enjoy the pay rise. While a now substantial theoretical literature addresses this and related issues, beginning with Olson's (1965) seminal contribution, thus far it is poorly understood how human decision makers actually behave in simple collective rent-seeking contests. Consider a setting where all group members reap the benefits of success, while the likelihood of success depends on the efforts of individual group members. If formal enforcement measures are absent, the conflict parties effectively compete on the basis of voluntary contributions although informal sanctions against defectors, like social ostracism or mobbing, may help to overcome the inherent freeriding incentives. To date we have no systematic empirical evidence on how inter-group conflict is likely to evolve in such a setting.

In the work we present here we use laboratory methods to study how conflict in contest games is influenced by parties being groups instead of individuals and by the existence of the possibility of punishment between members of a party. We believe that these two variables are important parts of a good simplified representation of the conditions under which social conflict takes place. We base our analysis on a version of Tullock's simple contest game in which two parties compete for an indivisible prize by investing into conflict budgets. The prize is characterised by rivalry in consumption and excludability at the level of conflict parties, but by non-rivalry in consumption and non-excludability within each conflict party. 
One can see this as a representation of a situation where the prize has a public good flavour for the successful party as is the case in some political confrontations in which all members of the winning party benefit from the outcome, much like in the example of industrial action mentioned earlier. In this setting the Nash equilibrium investment level is not affected by group size: while the non-rivalry in consumption property implies that adding a member to a group does not dilute the benefit of obtaining the prize for existing members, the new member's contribution to the group effort "crowds out" some of the existing members' contributions - in equilibrium to an extent that exactly counterbalances the new member's contribution itself. However, rivalry between actual groups and intra-group dynamics not captured by static equilibrium analysis may influence behaviour in ways that are not easy to predict. With groups as parties the equilibrium expenditure level can come about through different configurations of investments by the individual group members. Individuals' attempts to "free ride" on other party members' contributions may lead to overall lower expenditures than the ones predicted. At the same time, issues of inter-group competitiveness can conceivably push party members to higher than predicted investment levels.

The inclusion of within-group punishment possibilities in a static representation of conflict between groups has also no effect on the theoretical prediction since sanctioning other group members is a costly activity and can only be applied ex post - thus forward-looking players only motivated by own material payoffs will never use punishment. However, in a situation of strong rivalry between groups it may be used and have an influence on conflict expenditures. Starting with the influential paper by Fehr and Gächter (2000) a number of studies have analysed the effects of punishment on behaviour in public goods type of environments. ${ }^{1}$ The results may suggest that under certain circumstances punishment opportunities can have a positive effect on intra-group cooperation, but there is a fundamental difference between contributions to a public good game and contributions to a group conflict. While in the former case overall efficiency rises with the level of contributions, in the rent-seeking game contributions are unproductive waste. Thus, low contribution levels are socially desirable, and this may affect behaviour especially in a repeated game context.

Our results for the case without punishment show that expenditure levels in contests between groups are much higher than in contests between individuals, and both exceed equilibrium levels. On average, we observe that teams spend on conflict more than four times as much as predicted and about twice as much as single players. We also find that individual parties fighting against group parties invest similar levels to individual parties fighting against other individual parties. Group parties fighting against individual parties invest like group parties fighting against other groups.

In contests with punishment opportunities expenditure levels are in turn much higher than in any of the treatments without punishment. In the final rounds of the experiment, investments

\footnotetext{
${ }^{1}$ See, e.g. Falk, Fehr, and Fischbacher (2005), Sefton, Shupp, and Walker (2007), Masclet, Noussair, Tucker, and Villeval (2003), Nikiforakis (2004), and Denant-Boemont, Masclet, and Noussair (2007).
} 
in conflict are more than twice as high with punishment as without. The consequence is a large waste of resources: more than three quarters of the prize parties are fighting over are dissipated by direct conflict expenditures. However, to determine the true efficiency loss the costs imposed by punishment and the costs borne to punish others need to be added. These costs included, material losses are now $869 \%$ of the equilibrium level and rent dissipation is in excess of $100 \%$. These results strongly contrast with those from those public goods experiments where punishment tends to enhance efficiency.

\section{Experimental design and research questions}

All our treatments are based on the same contest game between two parties. Our design is composed of four treatments, which vary with respect to the number of individuals composing each of the two parties and with respect to the existence of punishment possibilities. The baseline treatment, which we call 1:1, consists of a conventional Tullock contest game with the two parties being individuals and without punishment. In two other treatments, called 1:4 and $4: 4$, one or both of the two parties are composed of a team of four individuals. ${ }^{2}$ In the treatment 4:4P we add the possibility of punishment in a way that will be explained below. In our dataset each group of two rival parties constitutes a statistically independent observation. We have data on 14 groups for the 1:1 treatment, 11 for $1: 4,8$ for $4: 4$ and 8 for $4: 4 \mathrm{P}$.

In field settings one typically observes repeated interactions among the same agents, and we therefore decided to let our subjects interact in fixed parties and with a fixed opponent party during the course of the twenty rounds of the experiment. This and all the features of the experiment that we refer to were common information to all participants. ${ }^{3}$

At the beginning of each round each participant received an endowment of 1000 points from us and could use these to buy "contest tokens" for his or her party. ${ }^{4}$ Each contest token cost 1 point and each subject could buy any integer amount of contest tokens between 0 and 1000 . Any points that were not spent on contest tokens were added to the participant's point balance. As soon as everybody had chosen how many contest tokens to buy, each participant was informed about how many tokens each of the other members of the own team had invested in that round (in teams of size one the participant was simply reminded of how much he/she had invested) and of the total amount invested by the rival party. Own team members were identified by a number which remained constant over the twenty rounds, so that others' behaviour could be traced over time. However, participants did not know the identity of the others in their team or the identity of their opponent(s).

\footnotetext{
${ }^{2}$ In the following we will use the term "team" to refer to a set of four players who jointly compete against a single player or another four-player team, and will reserve the term "group" to refer to a set of matched opponents. Furthermore, we will use the word "party" as a generic term for teams and single players.

${ }^{3}$ The appendix contains a copy of the instructions we use.

${ }^{4}$ The experiment was fully computerised using purpose-built software developed in Visual Basic.
} 
An on-screen lottery wheel was then used to determine which of the two parties would win the prize. The members of the winning party received an extra 1000 points each - thus, in parties composed of four individuals the team, if successful in the contest, received 4000 points in total. The probability of a party winning the prize was equal to the total number of tokens invested by that particular party divided by the sum of tokens invested by both parties. After the lottery each participant was informed of whether he or she, or his or her team, had won or lost. The prize money was added to the winning party members' point balances and in the treatments without punishment the experiment then proceeded to the next round.

In the 4:4P treatment, where punishment was possible, participants could, before moving to the next round, assign "deduction tokens" to each of the other own team members (not to members of the other team). Each deduction token received from a team-mate reduced a participant's point balance by 3 points. This could possibly wipe out a participant's earning from a particular round. ${ }^{5}$ In addition, each deduction token a participant assigned to a teammate reduced the participant's point balance further, by 1 point. Thus, punishing others was costly. The maximum number of deduction tokens that a participant could assign to others in a round was 500. Overall, this could lead to negative earnings in a particular round. ${ }^{6}$ Subjects were explicitly told that they could choose not to assign any deduction tokens by simply filling out a ' 0 ' in the corresponding field. After all team members had made their decisions on the allocation of deduction tokens, participants were informed about received punishment and point balances were updated. Then the experiment proceeded to the next round. All rounds developed in the same way.

The symmetric Nash equilibrium of this finitely repeated game, given the assumption that players are only motivated by their own money earnings, predicts that each party invests 250 points in contest tokens, regardless of whether the treatment is $1: 1,1: 4$ or $4: 4$. To see this formally, let $\pi_{i}\left(x_{i}, X, Y\right)$ denote the payoff of a representative player $i$, where $x_{i}$ is the number of contest tokens purchased by player $i, X$ is the sum of contest tokens purchased by player $i$ 's team ( $X=x_{i}$ when player $i$ is on his or her own) and $Y$ is the total number of contest tokens bought by the opponent party. Ignoring any endowment, the player's payoff function in this game can then be written as

$$
\pi_{i}\left(x_{i}, X, Y\right)=\frac{X}{X+Y} 1000-x_{i} .
$$

The first-order condition, derived in the usual way, is $(X+Y)^{2}=1000 Y$. The same calculation can of course be made for a representative member of the opponent party and hence we must have $X=Y$ in equilibrium. Therefore, the equilibrium per-party investment is $X^{*}=Y^{*}=250$, independently of team sizes.

\footnotetext{
${ }^{5}$ When the recipient of deduction tokens would nominally have earned a negative amount due to being punished, the computer disregarded the "excess" reduction and set the recipient's round earnings to zero.

${ }^{6}$ To avoid bankruptcies we gave participants in the 4:4P treatment a starting balance of 3000 points. Even with this extra endowment bankruptcies were still possible, but in the experiment this never occurred.
} 
Equilibrium theory provides a clear-cut solution at the level of conflict parties, but is silent about the behaviour of individual team members: any combination of investments by individual team members that add up to 250 constitutes an equilibrium.

In addition to the amount of equilibrium investment, the degree of equilibrium rentdissipation - the ratio of total resources spent in the contest to the value of the prize - is another benchmark against which one can compare behaviour. Because of the public good properties of the prize, its value is dependent on the size of the winning party. Taking this into account, the degree of equilibrium rent-dissipation with our parameters is $500 / 1000=0.5$ for the $1: 1$ treatment and $500 / 4000=0.125$ for both $4: 4$ treatments. In the 1:4 treatment the degree of rent-dissipation depends on whether the individual or the team wins the prize. In equilibrium the expected rent-dissipation level in this case is $(1 / 2) \cdot(500 / 1000+500 / 4000)$ $=0.3125$. Note that while the equilibrium investment levels are the same, the levels of equilibrium rent-dissipation vary across treatments, as a result of the difference in the effective prize across treatments.

The equilibrium prediction is also not affected by the existence of intra-team punishment possibilities. Using the standard backwards induction argument, it is clear that in the last round, after having seen team members' investments in contest tokens, nobody should be expected to invest in costly punishment tokens and continuing this argument one gets to the prediction that punishment will not be used in any of the rounds.

Table 1 summarises our design and the relevant predictions.

Table 1: Experimental design and equilibrium benchmarks

\begin{tabular}{|c|c|c|c|}
\hline \multirow[b]{2}{*}{ Treatment } & \multirow[b]{2}{*}{ Data generating process } & \multicolumn{2}{|c|}{ Standard equilibrium predictions } \\
\hline & & $\begin{array}{l}\text { Expenditures per } \\
\text { conflict party }\end{array}$ & $\begin{array}{c}\text { Rate of rent } \\
\text { dissipation }\end{array}$ \\
\hline $1: 1$ & 20 rounds, fixed matching, 14 ind. obs. & 250 points & $50.0 \%$ \\
\hline $1: 4$ & 20 rounds, fixed matching, 11 ind. obs. & 250 points & $31.3 \%$ \\
\hline $4: 4$ & 20 rounds, fixed matching, 8 ind. obs. & 250 points & $12.5 \%$ \\
\hline $4: 4 \mathrm{P}$ & 20 rounds, fixed matching, 8 ind. obs. & 250 points & $12.5 \%$ \\
\hline
\end{tabular}

Our research questions emerge directly from the equilibrium analysis above.

Question 1: Will participants in the 1:1 treatment involving only individuals invest equilibrium level quantities?

This first question is about establishing a baseline for the treatments involving teams. We are also curious in how far our data replicates results from previous contest experiments. As noted above, most studies find excessive rent-seeking expenditures relative to standard 
predictions. However, a few papers report contest behaviour close to equilibrium (Shogren and Baik, 1991) or even below equilibrium (Schmidt, Shupp and Walker, 2006).

Question 2: Will teams fighting teams invest more or less than individuals fighting individuals?

This is one of the key questions we are interested in and, as discussed in the introduction, a priori it is not at all clear what the answer is. One possibility is that groups end up investing less than individuals, since every member of a team might rely on the team-mates to contribute sufficiently to the team effort. Another possibility is that team rivalry and intrateam dynamics lead to more conflict than between individuals. There exists evidence in other contexts that groups can be more competitive than single players - see Bornstein and BenYossef (1994) - and a related effect could have an impact here.

Question 3: Will individuals and teams behave differently when competing against individuals than when competing against teams?

The answer to this question will be of interest as a means of understanding possible differences between the treatments involving only teams and only individuals.

Question 4: How will the possibility of within-team punishment affect conflict expenditures and to what extent will subjects use the punishment opportunities?

Again, a priori it is not clear how the presence of punishment possibilities will affect behaviour. One conjecture is that it will only be used to get team members who are taking a cheap ride on others' contest tokens to increase their contributions to the level of others. However, it may also be hypothesised that team members be punished for investing too much, since this decreases overall social efficiency.

\section{Procedures}

The experiment was conducted at the University of Nottingham. Subjects were recruited from a university-wide subject pool comprised of undergraduates who had indicated a willingness to be paid volunteers in decision-making experiments. Each subject participated in only one session, and no subject had taken part in experiments similar to the present one. On arrival, participants were seated at visually separated computer terminals. Information was only transmitted through the computer network and any other form of communication was prohibited. Subjects were not told with whom they interacted during the experiment, but they knew that the composition of groups did not change in the course of a session.

Each session began with a brief introductory talk after which the written instructions were read aloud. The total earnings of a subject were equal to the sum of all the profits he or she made during the experiment. Subjects were paid at the end of the experiment, in private and in cash, at a conversion rate of $1 \mathrm{p}$ per 30 points accumulated. Participants earned between $£ 3$ and $£ 11.70$ with an average of $£ 7.83$ for sessions lasting about 45 minutes including the time 
spent reading the instructions. At the time of the experiment, the exchange rate to other major currencies was approximately US-\$1.85, €1.45, RMB14 and $¥ 200$ for $£ 1$.

\section{Results on individuals versus teams}

In this section we report the results from treatments $1: 1,1: 4$ and 4:4. Section 4.1 concentrates on the main differences in behaviour across treatments. In sections 4.2 and 4.3 we will look in more detail at individual behaviour. In section 5 we will move to the analysis of the effects of the presence of punishment.

\subsection{Time trends, differences between treatments and between conflict parties}

Figure 1 shows how average contest expenditures evolve over time in all three treatments without punishment; this is per team so that for a team of four what is shown is the sum of contributions by all team members together. For the 1:4 treatment we plotted separate time series for teams and single players.

Figure 1: Contest expenditures over time in the no-punishment treatments

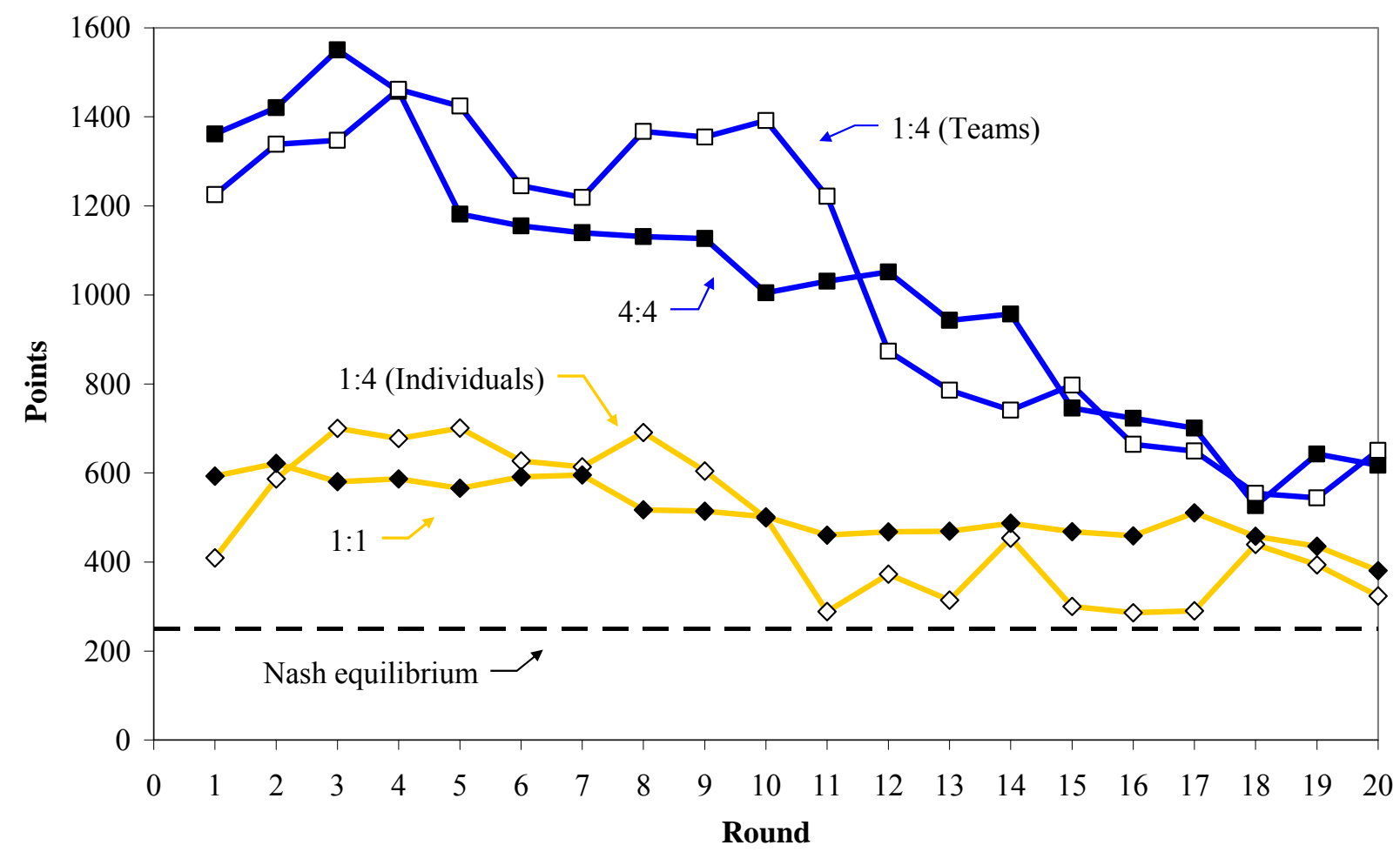

Based on the figure, three observations seem noteworthy. First, overall actual contest expenditures appear to be much higher than the equilibrium prediction. There is, however, a downward trend over time, particularly in the teams. Nevertheless, even towards the end of the experiment expenditures appear to be higher than in equilibrium. We will need to study to what extent the downward trend is significant over all twenty rounds. Second, on average teams invest much more than single players, although there appears to be some degree of 
convergence towards the end of the experiment. Third, there is a striking similarity in how much both teams and single players invest with different opponents - indeed, on first sight it nearly seems as if the conflict parties choose their expenditures independently of whether the opponent is a single player or a team. In the analysis below we try to uncover what is behind this regularity. We now move to a statistical analysis of these observations.

To examine to what extent there is a decline over time and when (if at all) this trend comes to a halt, we use the following three-step procedure. First, we calculate, for each of our 33 pairings (treating individuals and teams separately in the 1:4 treatment), the difference in average expenditures across the two halves of the data (rounds 1 to 10 versus rounds 11 to 20) and then employ a two-sided Fisher one-sample randomisation test for each treatment under the null hypothesis that the difference is zero. Second, we conduct the same analysis to compare the third and fourth quarter of the data (rounds 11 to 15 versus rounds 16 to 20). Finally, focusing on the final quarter, we compute for each pairing the Spearman rank order correlation coefficient $\left(r_{s}\right)$ between the round-data from the last five rounds and the round number, and then test for each treatment whether $r_{s}$ differs significantly from zero. The results of our trend analysis are shown in Table 2.

Table 2: Measures of time trends in expenditures (p-values in parentheses)

\begin{tabular}{|c|c|c|c|c|c|c|}
\hline & \multicolumn{2}{|c|}{$\begin{array}{l}\text { Rounds } 1-10 \text { vs. } 11-20 \text { : } \\
\text { Avg. differences }\end{array}$} & \multicolumn{2}{|c|}{$\begin{array}{l}\text { Rounds } 11-15 \text { vs. } 16-20 \text { : } \\
\text { Avg. differences }\end{array}$} & \multicolumn{2}{|c|}{$\begin{array}{l}\text { Rounds 16-20: Avg. } r_{s} \text { between } \\
\text { round-data and -number }\end{array}$} \\
\hline & Individuals & Teams & Individuals & Teams & Individuals & Teams \\
\hline $1: 1$ & $\begin{array}{r}-107.2 \\
(0.012)\end{array}$ & $\mathrm{n} / \mathrm{a}$ & $\begin{array}{l}-21.9 \\
(0.564)\end{array}$ & $\mathrm{n} / \mathrm{a}$ & $\begin{array}{l}-0.193 \\
(0.237)\end{array}$ & $\mathrm{n} / \mathrm{a}$ \\
\hline 1:4 & $\begin{array}{r}-264.7 \\
(0.007)\end{array}$ & $\begin{array}{l}-589.3 \\
(0.009)\end{array}$ & $\begin{array}{c}0.7 \\
(0.981)\end{array}$ & $\begin{array}{l}-271.5 \\
(0.050)\end{array}$ & $\begin{array}{l}0.065 \\
(0.766)\end{array}$ & $\begin{array}{l}-0.135 \\
(0.434)\end{array}$ \\
\hline $4: 4$ & $\mathrm{n} / \mathrm{a}$ & $\begin{array}{l}-459.0 \\
(0.039)\end{array}$ & $\mathrm{n} / \mathrm{a}$ & $\begin{array}{l}-303.7 \\
(0.008)\end{array}$ & $\mathrm{n} / \mathrm{a}$ & $\begin{array}{l}-0.063 \\
(0.796)\end{array}$ \\
\hline
\end{tabular}

As the table shows, there is strong evidence for a negative trend between the first and second half of the experiment. The effect is more pronounced for the teams but is also present in the data from individual players. However, for individuals the decline in investments does not appear to continue into the second half: differences between the third and fourth quarter are marginal and not statistically significant. In contrast, the teams continue to systematically lower their investments by substantial amounts even after entering the second half.

Note that in none of the treatments does our analysis indicate systematic trends within the final quarter of the experiment. After some rounds with considerable downward trends behaviour reaches a kind of rest point. 
We now look at conflict expenditure levels and compare them with the equilibrium level. Recall that in equilibrium each conflict party spends 250 points on contest tokens, regardless of team size. Averaging over all rounds, we observe that teams actually spend more than four times as much (1035 points) and single players about twice as much (498 tokens). When we focus on the final quarter of the experiment - for which there is no time trend in any of the treatments - we find that expenditures are still very high. In the last five rounds, teams in the 4:4 treatment spend on average 642 points and teams in the 1:4 treatment only slightly less than that (612 points). These deviations from the theoretical prediction are statistically significant: the p-values are 0.008 for the $4: 4$ teams and 0.017 for the 1:4 teams (two-sided Fisher one-sample permutation test). Single players in the last quarter of the 1:1 treatment invest on average 448 points ( $p$-value $=0.004)$, and only for single players in the 1:4 treatment (347 points on average in the last quarter) do we fail to reject the null hypothesis ( $\mathrm{p}$ value $=0.295){ }^{7}$ Our first result contains the answer to our question 1 above:

Result 1: In the 1:1 treatment average expenditures substantially and significantly exceed the equilibrium level. The material losses due to the (inherently unproductive) investments in the conflict amount to 205\% of the equilibrium level (179\% based on the last five rounds).

The finding that individual contestants invest excessively relative to standard predictions is consistent with the results reported in the majority of previous studies on behaviour in experimental contests.

Turning to observations 2 and 3 at the beginning of the section, we first use two-sample permutation tests to compare investment behaviour of individuals and teams across treatments. Based on all twenty rounds, we reject the null hypothesis that investment levels in contests between individuals are the same as investment levels between teams of four ( $p$ value $=0.001$, two-sided). Based on the last five rounds, the difference between the investment levels in the 1:1 and the 4:4 treatment is still substantial although no longer significant at conventional levels ( $\mathrm{p}$-value $=0.127$ ).

Result 2: Average contest expenditures in the 4:4 treatment are twice as high as in the 1:1 treatment (nearly one and a half times as high based on the last five rounds). The observed level of material losses is now 409\% of the Nash equilibrium level (257\% based on the last five rounds).

Comparing the behaviour of individuals and teams within the 1:4 treatment we find that team expenditures exceed single players' expenditures by $118 \%$ (77\% based on the last five rounds). A two-sided Fisher permutation test based on the difference between individual and team investment in each 1:4 pairing yields p-values of 0.001 (all 20 rounds) and 0.012 (last 5 rounds). Thus, teams continue to be the dominant conflict party up to the end - any tendency of convergence between teams and single players that Figure 1 might suggest is at least far from complete.

\footnotetext{
${ }^{7}$ Not surprisingly, based on all twenty rounds the null hypothesis would be rejected in all treatments.
} 
Finally, to answer Question 3 above, we fail to reject the null hypothesis that individuals behave identically in the 1:1 and the 1:4 treatments, regardless whether this comparison is based on all twenty rounds ( $p$-value $=0.669)$ or just the last five ( $p$-value $=0.306)$. The same is true for teams when we compare the 1:4 with the 4:4 treatment (p-value all 20 rounds $=$ 0.925 ; $\mathrm{p}$-value last 5 rounds $=0.876$ ).

Result 3: Single players' expenditure levels are not significantly different in the 1:1 and 1:4 treatments. Team expenditure levels are not significantly different in the 4:4 and 1:4 treatments.

\subsection{Responsiveness of conflict parties to opponents' behaviour}

The previous subsection leaves us with a puzzle: the behaviour of single players and teams with respect to investment levels as well as adjustments over time - does not vary systematically with the type of opponent, despite that these different types make vastly different choices! Finding out what is behind this regularity will allow us to better understand observed behaviour.

We address this question using Figure 2, which shows average contest expenditures per conflict party in the final quarter of the experiment. Consider the data for the 1:4 treatment shown in the middle of the figure and note first that there is considerable variability in behaviour across single players (the coefficient of variation is 0.807 ) and across teams (the coefficient of variation is 0.700 ). However, we find strong evidence that this variability is not independent across the conflict parties: the Spearman rank order correlation coefficient between individuals and teams is 0.679 , and under the null hypothesis that there is no correlation we obtain a two-sided $p$-value of 0.022 . A very similar picture emerges in the $1: 1$ treatment - there appears to be a lot of variation across groups but quite similar behaviour within each group. Since we deal with unordered pairs in this treatment, we compute the single-measure intraclass correlation coefficient and obtain a value of 0.835 (two-sided pvalue $<0.001)$. This correlation suggests that the behaviour of the contest parties is to a considerable degree dependent on the history of interaction between them.

In $4: 4$ there is again a lot of variation across groups, yet here the correlation between opposing teams, though positive, is much less pronounced and not statistically significant: the intraclass correlation coefficient is only 0.363 (two-sided p-value $=0.155$ ).

Why is the correlation between opponents lower in the team-versus-team treatment than in the other two treatments? We suggest two alternative explanations. The first is that intra-team dynamics influence the decisions of individual team members and "distract" them from the simultaneous interaction with the rival. Thus, according to this explanation, while single players try to "best respond" to their rival in the broadest sense (whoever that rival is) teams tend not to do that to the same extent. This would imply that it is mainly the single players, not the teams that produce the high correlation we observe in the 1:4 treatment. The alternative explanation is based on the thought that teams may be expected to display more 
erratic and inconsistent behaviour relative to single players because four individuals are involved in each investment decision. As a result, the nature of one's interaction with a rival team may be seen as "less strategic" than with a rival single player. Taking this into account, the opponent of a team (whether this opponent is a single player or a member of a rival team) would find it less advantageous to try to react to the team's round-by-round decisions.

Figure 2: Average contest expenditures per conflict party (in points) (based on last five rounds)

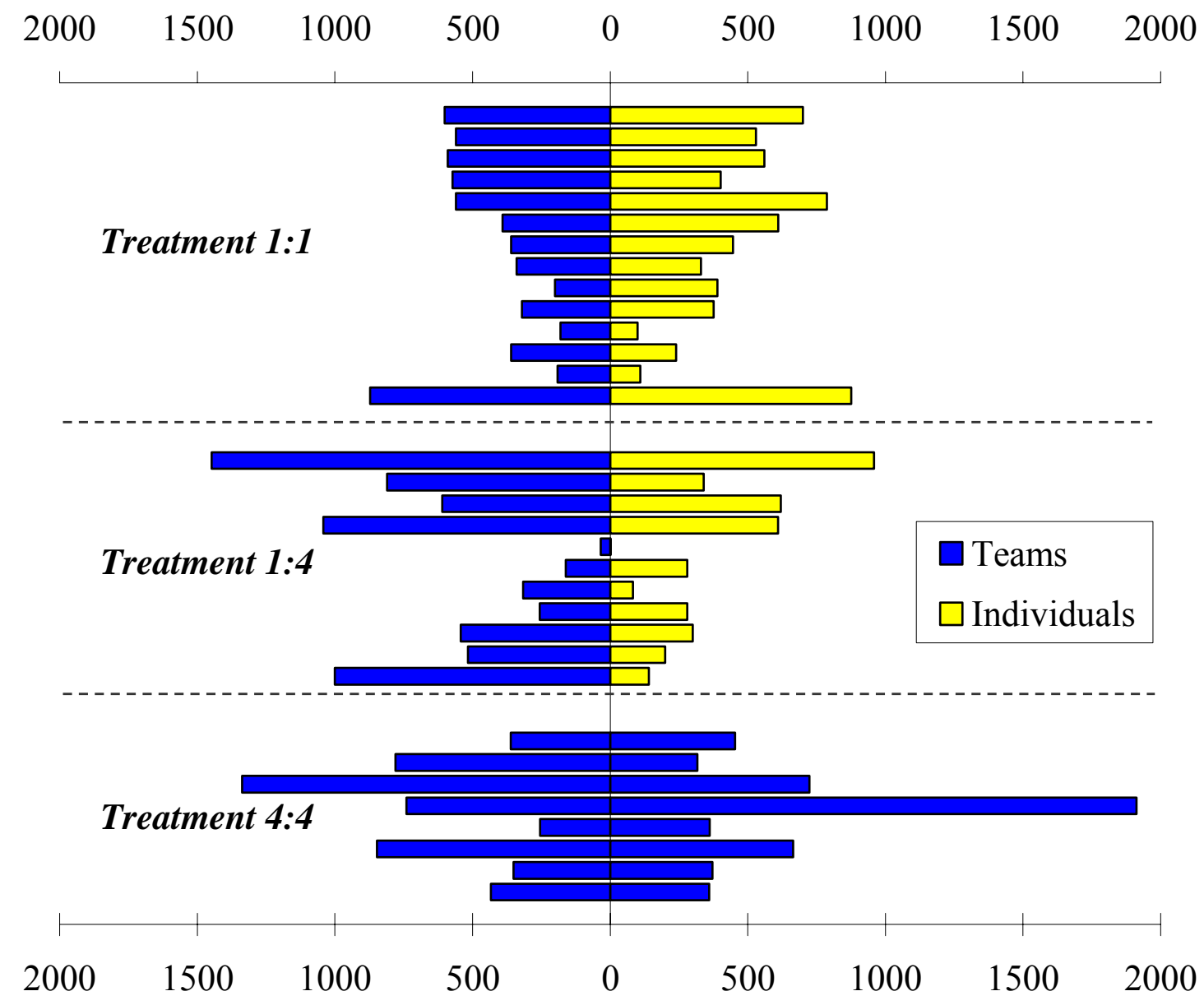

Put simply, the question is whether teams tend to ignore the behaviour of their opponents or whether teams' opponents tend to ignore teams' behaviour. To investigate the two competing hypotheses we ran a number of regressions that analyse to what extent conflict parties make their current investment decisions dependent on decisions in the preceding round. As independent variables we included the parties' own and their opponents' lagged expenditures as well as the current round number to control for the time trend we observed in our earlier analysis. To account for the possibility of nonlinearities in a party's response to its rival's choices we also included a squared term for the opponent's expenditure in $t-1$.

Table 3 shows the regression results. The coefficients for own lagged expenditures are positive and highly significant in all treatments, which indicates the presence of a considerable degree of path dependency. The coefficients for the opponent's lagged 
expenditures give more support to our second than to our first interpretation of the observed patterns of correlation: the coefficients for single players in the 1:1 treatment and for teams in the 1:4 treatment are nearly as high as the own lagged investment coefficients and are statistically significant, whereas the coefficients for single players in the 1:4 treatment and for teams in the 4:4 treatment are much lower and not statistically significant. Thus, both single players and teams appear to make adjustments to their investments depending on their opponent's preceding choice, but only if that opponent is a single player, not if the opponent is a team. ${ }^{8}$ In other words, opponents of teams tend to ignore the round-by-round variation in those teams' behaviour. Focusing on the 4:4 treatment in particular, the results from Table 3 suggest that competing teams do no pay too much attention to each other.

Table 3: Determinants of individual and team expenditures in round $t^{\dagger}$

\begin{tabular}{|c|c|c|c|c|}
\hline \multirow[b]{2}{*}{$\begin{array}{l}\text { Independent } \\
\text { variables }\end{array}$} & \multicolumn{4}{|c|}{ Dependent variable: Conflict party's investment in $t$} \\
\hline & $\begin{array}{c}1: 1 \\
\text { Single players }\end{array}$ & $\begin{array}{c}1: 4 \\
\text { Single players }\end{array}$ & $\begin{array}{c}1: 4 \\
\text { Teams }\end{array}$ & $\begin{array}{c}4: 4 \\
\text { Teams }\end{array}$ \\
\hline Constant & $\begin{array}{c}174.433 * * * \\
(52.1690)\end{array}$ & $\begin{array}{l}227.106^{*} \\
(103.4751)\end{array}$ & $\begin{array}{c}96.258 \\
(79.0700)\end{array}$ & $\begin{array}{l}231.496^{*} \\
(108.5051)\end{array}$ \\
\hline Round & $\begin{array}{c}-3.894 * * \\
(1.6486)\end{array}$ & $\begin{array}{l}-9.535^{*} \\
(4.4108)\end{array}$ & $\begin{array}{c}-8.242^{* *} \\
(3.3910)\end{array}$ & $\begin{array}{c}-9.518 \\
(5.0468)\end{array}$ \\
\hline $\begin{array}{l}\text { Own expenditure in } \\
t-1\end{array}$ & $\begin{array}{l}0.411 * * * \\
(0.0814)\end{array}$ & $\begin{array}{l}0.525 * * * \\
(0.1007)\end{array}$ & $\begin{array}{l}0.686 * * * \\
(0.0682)\end{array}$ & $\begin{array}{l}0.750 * * * \\
(0.0447)\end{array}$ \\
\hline $\begin{array}{l}\text { Rival's expenditure } \\
\text { in } t-1\end{array}$ & $\begin{array}{l}0.372 * * * \\
(0.0746)\end{array}$ & $\begin{array}{c}0.158 \\
(0.0885)\end{array}$ & $\begin{array}{c}0.638^{*} \\
(0.3021)\end{array}$ & $\begin{array}{c}0.112 \\
(0.081)\end{array}$ \\
\hline \multirow[t]{2}{*}{$\begin{array}{l}\text { (Rival's expenditure } \\
\text { in } t-1)^{2}\end{array}$} & $\begin{array}{c}-0.000 \\
(0.0001)\end{array}$ & $\begin{array}{c}-0.000 \\
(0.0000)\end{array}$ & $\begin{array}{c}-0.000 \\
(0.0003)\end{array}$ & $\begin{array}{c}-0.000 \\
(0.0000)\end{array}$ \\
\hline & $\begin{aligned} N & =532 \\
\mathrm{~F}(4,13) & =47.88 \\
\operatorname{Pr}>\mathrm{F} & =0.000 \\
\mathrm{R}^{2} & =0.363\end{aligned}$ & $\begin{aligned} N & =209 \\
\mathrm{~F}(4,10) & =66.17 \\
\text { Pr. }>\mathrm{F} & =0.000 \\
\mathrm{R}^{2} & =0.422\end{aligned}$ & $\begin{aligned} N & =209 \\
\mathrm{~F}(4,10) & =46.57 \\
\operatorname{Pr}>\mathrm{F} & =0.000 \\
\mathrm{R}^{2} & =0.723\end{aligned}$ & $\begin{array}{r}N=304 \\
\mathrm{~F}(4,7)=220.69 \\
\operatorname{Pr}>\mathrm{F}=0.000 \\
\mathrm{R}^{2}=0.664\end{array}$ \\
\hline
\end{tabular}

${ }^{\dagger}$ Numbers in parentheses are robust standard errors clustered on groups. Significance at the 10\%, $5 \%$ and $1 \%$ level is denoted by $*$,** and ${ }^{* * *}$ respectively.

\subsection{Behaviour of individual team members}

To gain more insight into how teams arrive at their conflict investment decisions we now look at behaviour of individual team members. Within our teams we find substantial heterogeneity in behaviour. This is illustrated in Figure 3. To construct the figure we have, for each team and each quarter of the experiment, ranked the contest expenditures of the individual team members and then computed across all teams the average expenditures of the highest, second highest, third highest and lowest contributors, respectively. In the absence of heterogeneity within teams there would be no difference between the highest and the lowest contributors. In

\footnotetext{
${ }^{8}$ In none of the treatments do we find evidence of nonlinearities in players' responses to opponents' lagged investments.
} 
contrast, in our data we find extreme differences between team members from the start. In the first quarter of both treatments involving teams, the lowest investor spends less than a third of the highest investor. Although investments then generally decline over time in all ranks (not always monotonically), there is no evidence that team members' behaviour converges. Indeed, in the last quarter the lowest contributor in 1:4 spends only $9 \%$ of the highest contributor and in $4: 4$ only $12 \%$. Thus, in relative terms the spread is even higher towards the end than in the early rounds.

Figure 3: Average expenditures of ranked team members (in points)

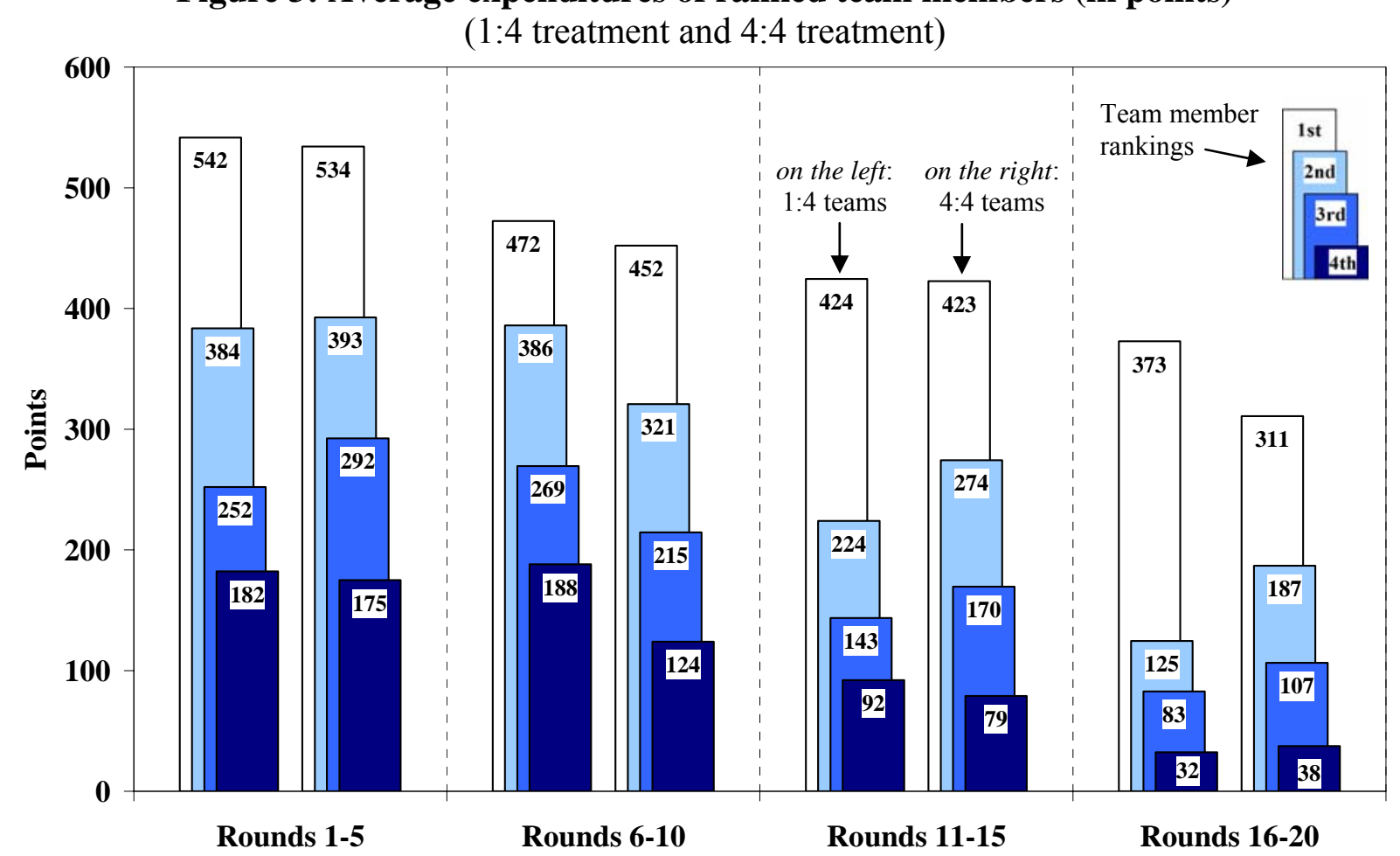

How important is the top contributor for the team performance? Consider the 1:4 treatment. While teams invest more than their single-player opponents, the investment per person is generally significantly lower for team members than for individual players (the p-values for each quarter are 0.004, 0.014, 0.056 and 0.018). However, we cannot reject the null when we focus on the top contributors (p-values: $0.756,0.154,0.398$ and 0.722 ). In other words, the top contributors on their own put their teams on an even footing with their single player opponents.

While this analysis is based on ranking team members separately for each quarter of the experiment, it is interesting to note that the orderings of individuals within teams are remarkably persistent over time. For instance, Kendall's coefficient of rank concordance across the four quarters is greater than 0.5 in 20 of our 27 teams. Indeed, in the last quarter the top contributors of the first quarter still spend more than their team-mates, about 2.3 times as much as the bottom-ranked team members of the first quarter. 
Thus, we find strong evidence that our subjects, who by design have identical positions in the experiment and whose identity is kept anonymous, do not behave symmetrically when interacting as members of a team. Some individuals behave as if they were activists and they do not seem to get tired of behaving that way.

The dynamics of choices of the team member who contributes most over the course of a session appear to differ from those of other team members. Table 4 extends our regression analysis above and considers individual team members as the unit of observation, separately for each team's "top contributor" (based on the average over all rounds) and the other team members. As before, the results indicate a significant correlation between current and own lagged expenditure. ${ }^{9}$

Table 4: Determinants of team members' conflict expenditures in round $t^{\dagger}$

\begin{tabular}{|c|c|c|c|c|}
\hline \multirow[b]{2}{*}{ Independent variables } & \multicolumn{4}{|c|}{ Dependent variable: Team members' contest expenditure in $t$} \\
\hline & $\begin{array}{c}1: 4 \\
\text { Top contributors }\end{array}$ & $\begin{array}{c}1: 4 \\
\text { Others }\end{array}$ & $\begin{array}{c}4: 4 \\
\text { Top contributors }\end{array}$ & $\begin{array}{c}4: 4 \\
\text { Others }\end{array}$ \\
\hline Constant & $\begin{array}{l}6.021 \\
(56.7962)\end{array}$ & $\begin{array}{l}52.336^{* *} \\
(23.4015)\end{array}$ & $\begin{array}{l}206.937 * * \\
(85.3716)\end{array}$ & $\begin{array}{l}18.820 \\
(16.0863)\end{array}$ \\
\hline Round & $\begin{array}{l}1.219 \\
(2.2865)\end{array}$ & $\begin{array}{l}-3.323 * * \\
(1.2873)\end{array}$ & $\begin{array}{l}-6.254^{*} \\
(3.2489)\end{array}$ & $\begin{array}{l}-1.022 \\
(0.8210)\end{array}$ \\
\hline $\begin{array}{l}\text { Own expenditure } \\
\text { in } t-1\end{array}$ & $\begin{array}{l}0.566^{* * *} \\
(0.1164)\end{array}$ & $\begin{array}{l}0.298 * * * \\
(0.0585)\end{array}$ & $\begin{array}{l}0.392 * * * \\
(0.1014)\end{array}$ & $\begin{array}{l}0.352 * * * \\
(0.0649)\end{array}$ \\
\hline $\begin{array}{l}\text { Rival's expenditure } \\
\text { in } t-1\end{array}$ & $\begin{array}{l}0.178 * * \\
(0.0731)\end{array}$ & $\begin{array}{l}0.134 * * * \\
(0.0138)\end{array}$ & $\begin{array}{l}-0.027 \\
(0.0299)\end{array}$ & $\begin{array}{l}0.033 * \\
(0.0142)\end{array}$ \\
\hline $\begin{array}{l}\text { Lowest of the team-mates' } \\
\text { expenditures in } t-1\end{array}$ & $\begin{array}{l}-0.124 \\
(0.1628)\end{array}$ & $\begin{array}{l}0.468 * * * \\
(0.0818)\end{array}$ & $\begin{array}{l}0.234 \\
(0.2365)\end{array}$ & $\begin{array}{l}0.298 * * * \\
(0.0823)\end{array}$ \\
\hline $\begin{array}{l}\text { Median of the team-mates' } \\
\text { expenditures in } t-1\end{array}$ & $\begin{array}{l}-0.100 \\
(0.2339)\end{array}$ & $\begin{array}{l}-0.007 \\
(0.0488)\end{array}$ & $\begin{array}{l}-0.014 \\
(0.2888)\end{array}$ & $\begin{array}{l}0.058 \\
(0.0734)\end{array}$ \\
\hline \multirow[t]{2}{*}{$\begin{array}{l}\text { Highest of the team-mates, } \\
\text { expenditures in } t-1\end{array}$} & $\begin{array}{l}0.322 * * \\
(0.1051)\end{array}$ & $\begin{array}{l}0.008 \\
(0.0274)\end{array}$ & $\begin{array}{l}0.298 * * * \\
(0.0797)\end{array}$ & $\begin{array}{l}0.090 * * * \\
(0.0177)\end{array}$ \\
\hline & $\begin{aligned} N & =209 \\
\mathrm{~F}(6,10) & =60.26 \\
\operatorname{Pr}>\mathrm{F} & =0.000 \\
\mathrm{R}^{2} & =0.529\end{aligned}$ & $\begin{aligned} N & =627 \\
\mathrm{~F}(6,10) & =84.93 \\
\operatorname{Pr}>\mathrm{F} & =0.000 \\
\mathrm{R}^{2} & =0.468\end{aligned}$ & $\begin{aligned} N & =304 \\
\mathrm{~F}(6,7) & =38.07 \\
\operatorname{Pr}>\mathrm{F} & =0.000 \\
\mathrm{R}^{2} & =0.322\end{aligned}$ & $\begin{aligned} N & =912 \\
\mathrm{~F}(6,7) & =16920 \\
\operatorname{Pr}>\mathrm{F} & =0.000 \\
\mathrm{R}^{2} & =0.391\end{aligned}$ \\
\hline
\end{tabular}

To further examine the dynamics of contest expenditures within teams we introduce lagged variables for the contributions of the three team-mates of an individual. The data suggests that top investors pay attention and positively respond to the highest of the other three

\footnotetext{
${ }^{9}$ Also consistent with what we have found above, the results of Table 3 suggest that the opponent's lagged expenditure has a greater impact on team members' decisions in 1:4 than in 4:4.
} 
investments. The correlation between their choices and the lowest of the other three investments, on the other hand, is not statistically significant.

In contrast, we find that team members who are not "top contributors" appear to pay attention to the lowest of the other three investments but appear to care little about the highest investment. ${ }^{10}$ Hence, the idea that top contributors particularly spur on their team-mates is not well supported by our data. One interpretation of this pattern is that non-top contributors are principally self-motivated in their decisions but are also concerned about being exploited by a low performer who free rides on the team's effort. However, it should be kept in mind that the role of a low contributor is ambiguous in the context of a collective rent seeking contest. While expending resources in the conflict involves a positive externality for other team members, it imposes a negative externality on the other party and reduces efficiency overall. In this sense, low expenditures could be viewed as exemplary and may affect the decisions of other team members for that reason.

\section{Results on the effects of punishment opportunities}

As in Section 4 we first focus on aggregate behaviour and move later to a more detailed analysis of several features of the results.

\subsection{Time trends, differences between treatments and between conflict parties}

Figure 4 shows average contest expenditures over time for the 4:4 and the 4:4P treatments; for the latter case we show conflict investment both with and without counting punishment costs. Recall that the graphs show per-team investments and that the benefit a team obtains from winning the contest is 4000 points overall. The figure reflects the data from eight groups for each treatment. In 4:4P average direct contest expenditures are remarkably high over the whole range and in some rounds the sum of expenditures across the two rival parties is not far from 4000 , the value of the prize itself. The comparison with the 4:4 treatment shows that the punishment opportunities facilitate this new persistence in fierce inter-team competition. Moreover, punishment is not merely a hypothetical threat - it is actually used. Additional point losses due to intra-team sanctions constitute an indirect form of investment in the contest activities of a team. Figure 4 illustrates that, if we take into account these indirect contest expenditures, the total material losses are increased by a quite substantial amount.

The development of the gap between the two 4:4P time series in Figure 4 indicates that, like the direct investments themselves, punishment activities are relatively stable over time. Over the course of the experiment, the average per-round number of deduction tokens a team member allocates to other team members fluctuates around 40 (with a standard deviation of 9.5) and the average in the last quarter is 42 . There is no endgame effect of the kind that one often observes in other environments. Note also that the level of punishment is less than $10 \%$

\footnotetext{
${ }^{10}$ In the 4:4 treatment the correlation between non-top contributors' expenditures and the lagged highest expenditure of their team-mates is statistically significant. However, the coefficient is quite low.
} 
of its maximum value of 500. Nevertheless, this level suffices to cause considerable point losses at the level of teams: recall that each deduction token costs the punisher 1 point and normally reduces the receiver's point balance by 3 points. Hence, the average cost of punishment activities amounts to about 498 points per round and team.

Figure 4: Contest expenditures over time in the 4:4 and 4:4P treatments

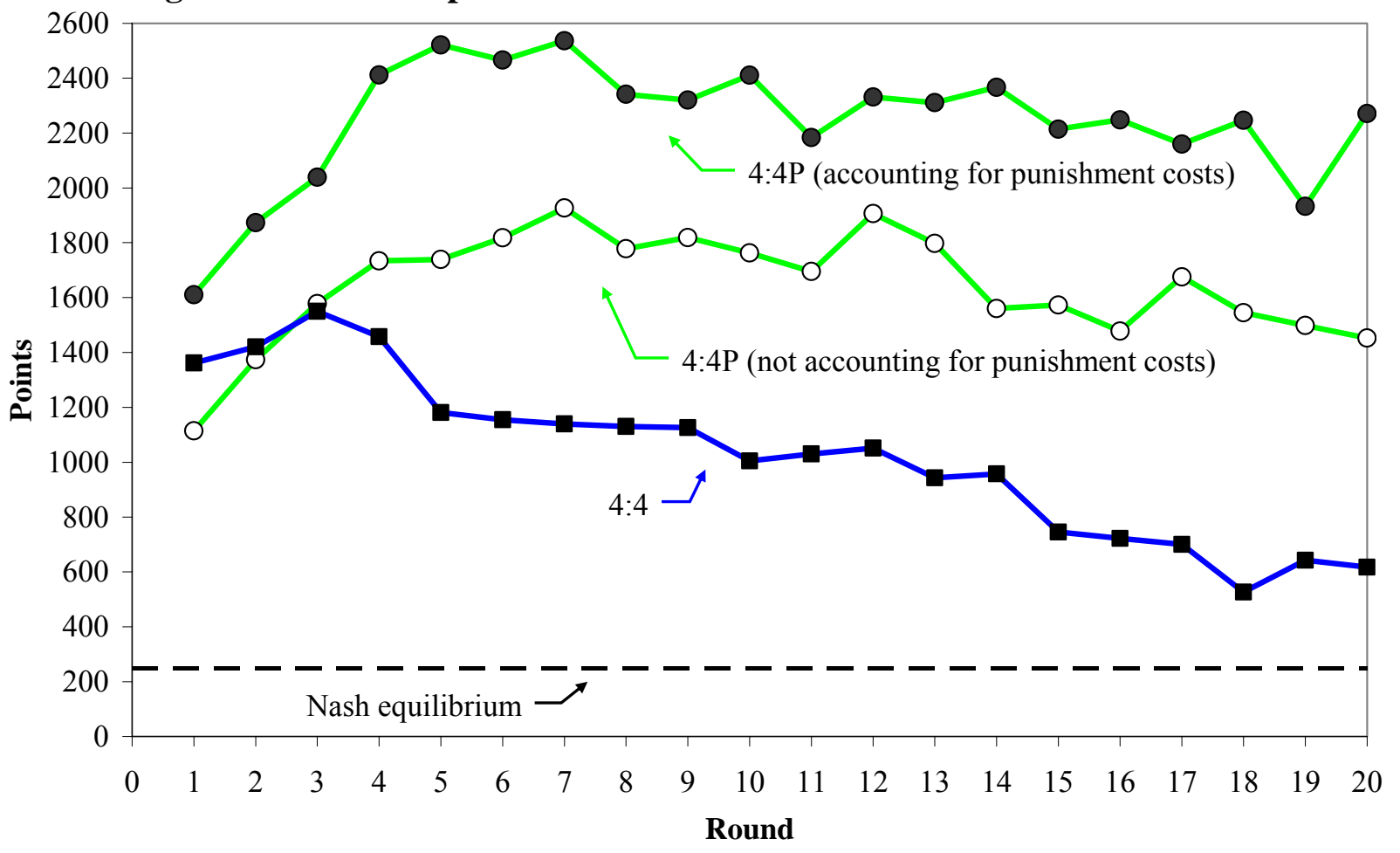

Table 5 examines measures of trends over time more formally, using the same procedure as for Table 2. Comparing direct, as well as indirect, contest expenditures across the first and the second half of the sessions, we cannot reject that the levels are equal. Similarly, there is no statistically significant time trend across the last two quarters and within the last five rounds.

Table 5: Measures of time trends in expenditures and punishment (Treatment 4:4P, $\mathrm{p}$-values in parentheses)

Rounds 1-10 vs. 11-20: Rounds 11-15 vs. 16-20: Rounds 16-20: Avg. $r_{s}$ between Avg. differences Avg. differences round-data and-number

\begin{tabular}{lccc}
\hline Contest & -46.1 & -176.6 & -0.301 \\
expenditure & $(0.860)$ & $(0.110)$ & $(0.125)$ \\
Punishment & 1.1 & 4.0 & 0.087 \\
activity & $(0.867)$ & $(0.547)$ & $(0.734)$ \\
\hline
\end{tabular}

Focusing on the last quarter of the experiment, for which we know that contest expenditures in the 4:4 treatment level off, we find a large and significant difference between the two treatments. A two-sample permutation test to examine the difference between the $4: 4$ 
treatment (642 points per team in the last five rounds) and the 4:4P treatment (1530 points, not accounting for punishment costs) yields a p-value of 0.006 .

Using the observed levels of investment in contest tokens and in punishment tokens we can now move to a more complete view of the material losses incurred in the 4:4P treatment. In doing this we consider, for a broader comparison, data from all four treatments.

Figure 5 shows for each of our treatments the actual levels of rent dissipation for each quarter of the experiment and also the corresponding equilibrium rent dissipation level. For the 4:4P treatment we show the rent dissipation levels with and without punishment costs. To calculate rent dissipation in the 1:4 treatment we relate the observed contest expenditures in a particular round and group to the rent that has actually been produced in that round - 1000 if the single player has won the prize, 4000 if the team has won. The relevant equilibrium prediction is calculated similarly as the expected level of rent dissipation.

Figure 5: Actual and equilibrium rent dissipation

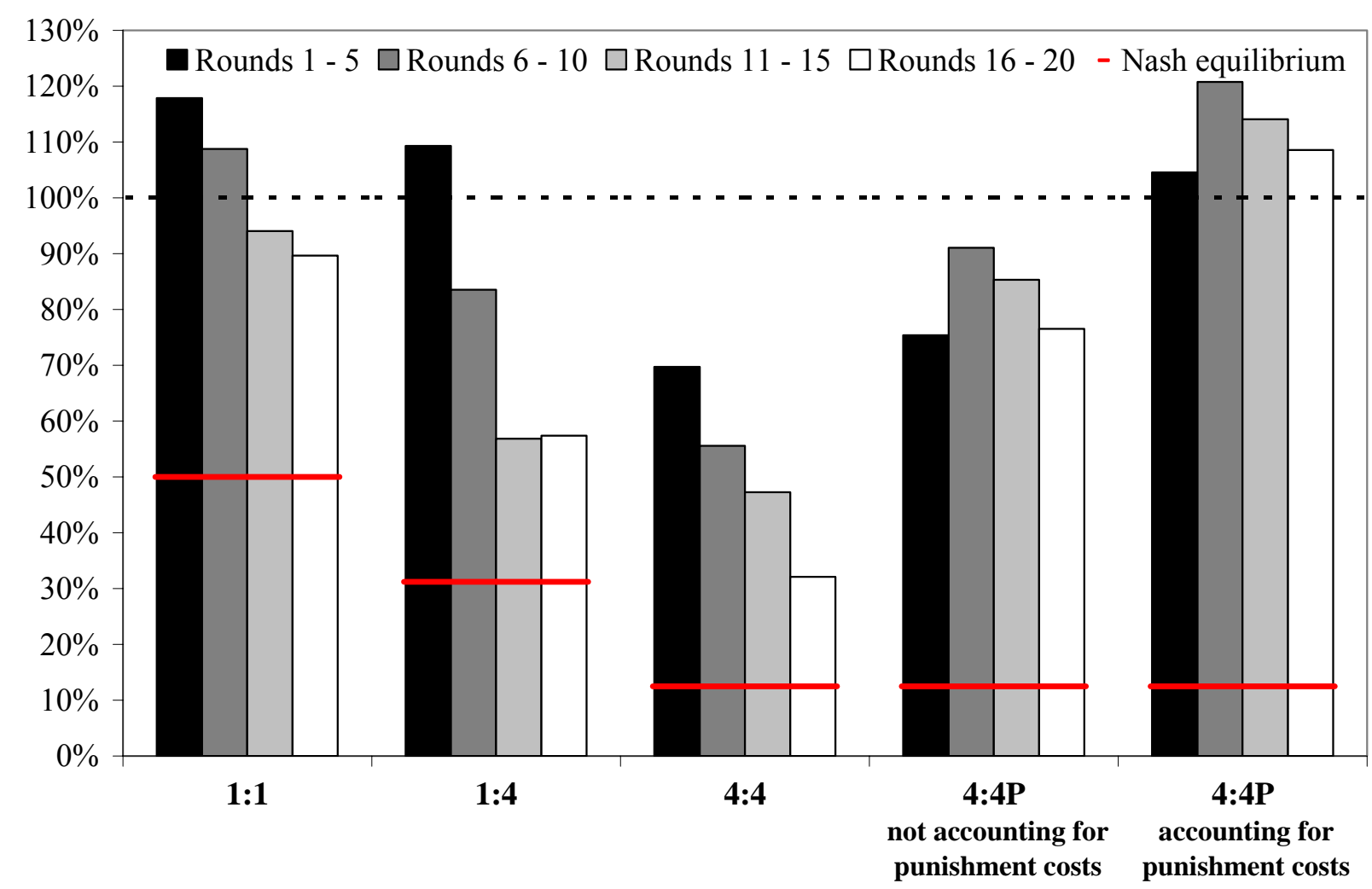

The two crucial features of the graph are the actual rent dissipation levels in absolute terms and in relative terms when compared to the corresponding equilibrium prediction. One can see that the absolute level in the 1:1 treatment is extremely high. The relative levels, on the other hand, are highest for the team-versus-team treatments. When we account for punishment costs, the level of rent dissipation in 4:4P exceeds that in 1:1 even in absolute terms, despite the fact that the equilibrium level rent dissipation in $4: 4 \mathrm{P}$ is only a quarter of that in $1: 1$.

We can now formulate the answer to our fourth question above in the following result. 
Result 4: In the 4:4P treatment average contest expenditures are 60\% above those in the 4:4 treatment (119\% above based on the last five rounds). The observed level of material losses is now $657 \%$ of the Nash equilibrium level (612\% based on the last five rounds). Adding the costs of punishment the observed level of material losses is $896 \%$ of the Nash equilibrium level (869\% based on the last five rounds).

\subsection{Details of investment and punishment behaviour}

Like in the treatments without punishment opportunities, we again observe considerable variation of behaviour across groups (recall that the term "group" refers to two teams together), as illustrated in Figure 6. Not accounting for punishment costs, total expenditures per group in the last quarter range from 1348 points to 5633 points, the latter figure being more than four times as high as the former (note also that the corresponding equilibrium prediction is 500 points). Compared to the $4: 4$ treatment we find that the correlation of expenditures between the two teams of a group is slightly more substantial, with an intraclass correlation coefficient of 0.454 and a p-value of 0.097 . However, if we include the punishment expenditures the correlation is weaker again, with an intraclass correlation coefficient of 0.301 and a p-value of 0.201 .

Figure 6: Average contest expenditures per conflict party (in points) (based on last five rounds)

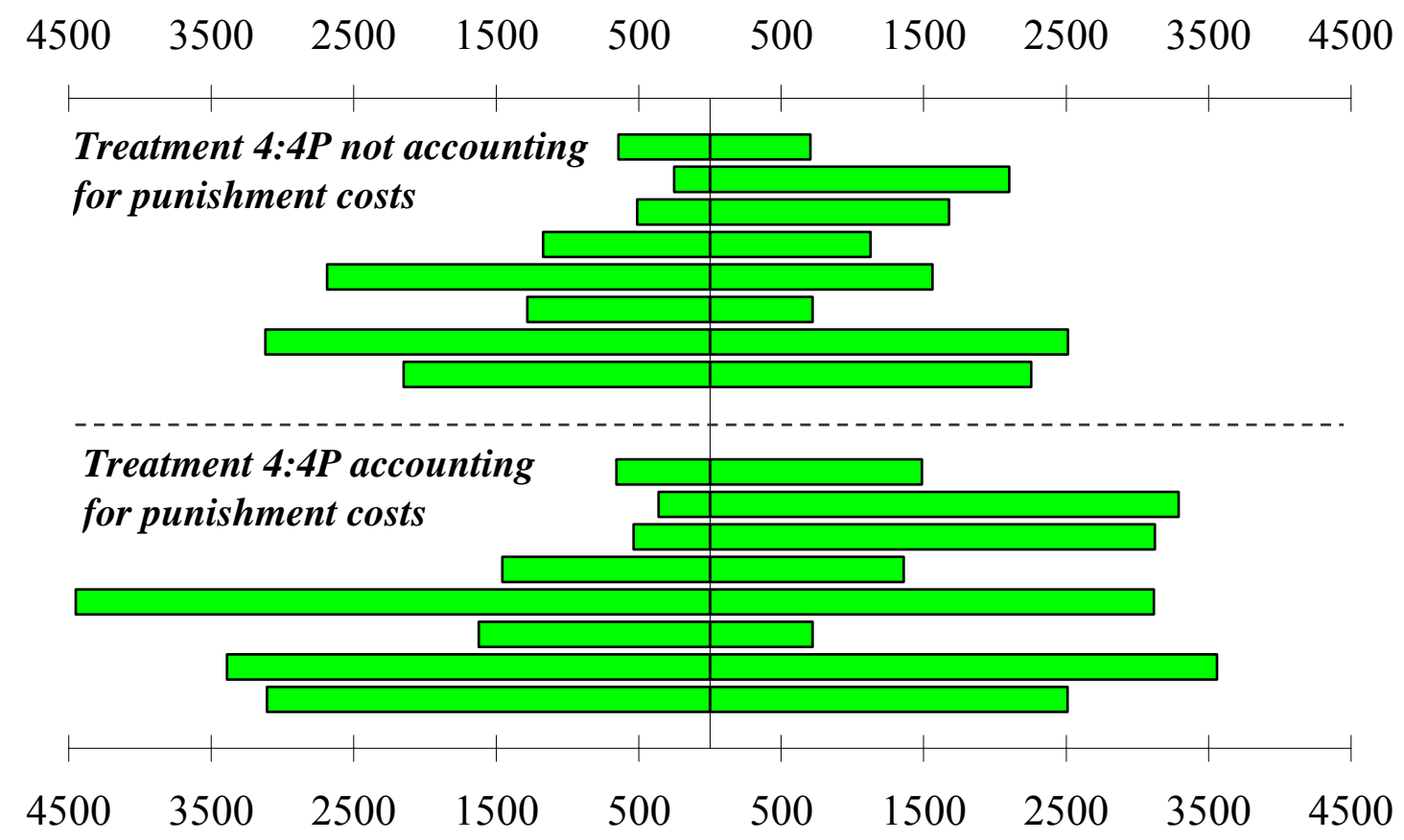

Turning to the question who punishes and who is punished, Figure 7 shows how getting punished depends on one's investment in relation to team members' average investment in the preceding round. Clearly, investing too little is what gets punished, whereas deviating upwards does not have any effect of triggered punishment. Additionally, Figure 7 shows how the amount of punishment imposed on others depends on the punisher's contribution to the 
team effort in relation to the other three team members' average contribution. Generally, the more somebody invests the more he will tend to punish. The data shown in the figures are easy to summarise: the more one deviates downwards from the team average the more one gets punished, and most of this punishment comes from those who contribute most to the team effort. Note that these regularities are rather in line with the findings reported in Fehr and Gächter (2000) that subjects in public goods games were more heavily punished the more their contribution fell below the average contribution of other groups members and that contributions above the average were punished much less and did not elicit a systematic punishment response.

Figure 7: Received/Active punishment in relation to own relative expenditures (in italics: number of data points behind each average)

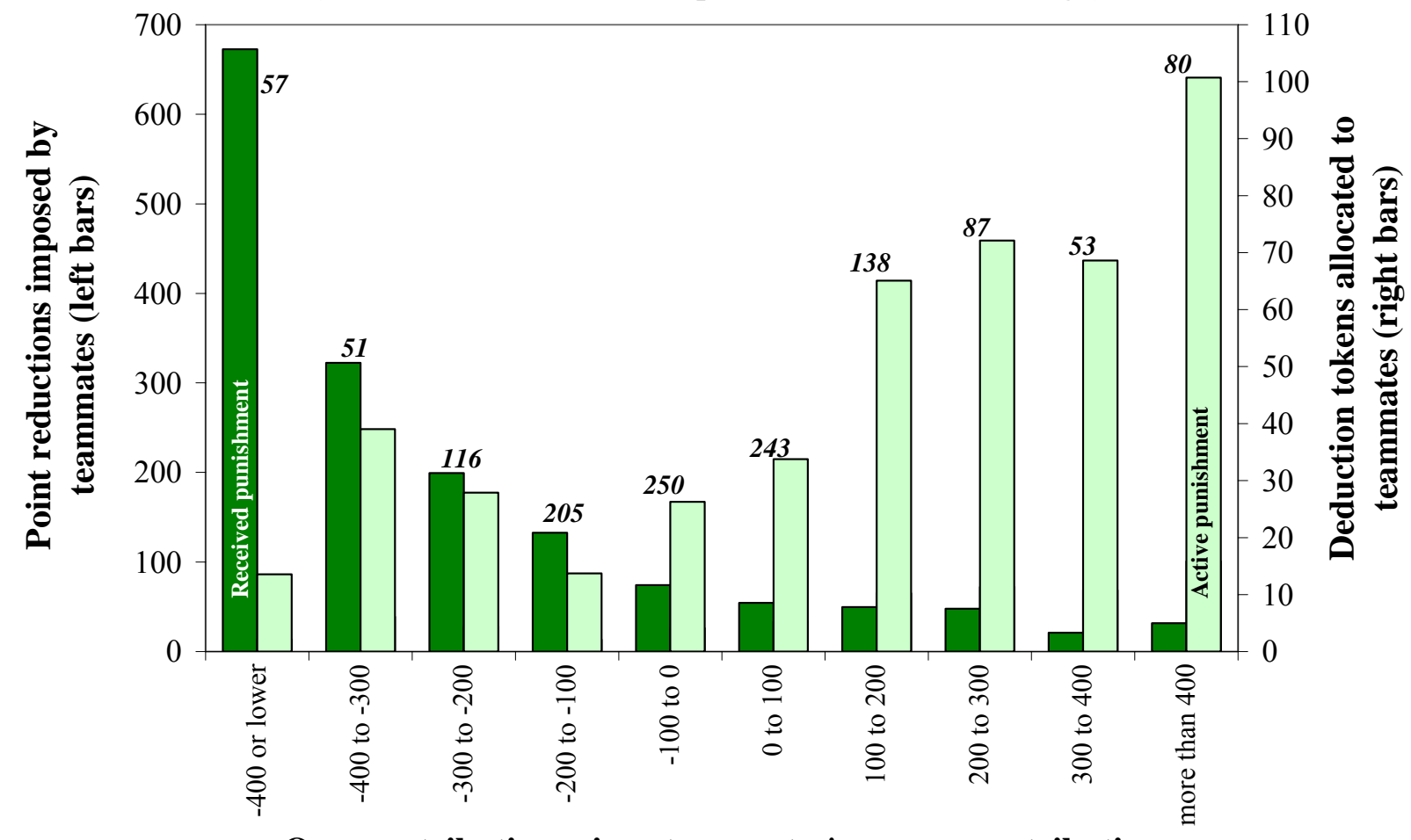

Own contribution minus teammates' average contribution

One effect of the introduction of punishment opportunities is a decrease in the heterogeneity among team members compared to the $4: 4$ treatment. We show this in Figure 8, which is constructed in the same way as Figure 3 in Section 4.3 above. While there still are considerable differences between the stronger and weaker performers in a team, they are less pronounced, particularly in the later rounds. For example, in the last quarter of the experiment the lowest contributor now spends $52 \%$ of the highest contributor, compared to only $12 \%$ in the $4: 4$ treatment. Also unlike in the $4: 4$ treatment the disparities within teams do not increase over time - if anything team members behave more homogenously towards the end of the experiment than at the beginning. The figure also shows how dispatched and received punishment is distributed among the ranked team members. Consistent with Figure 7, topranked team members punish on average more than, and get punished less than, any of the 
other team members - conversely, bottom-ranked team members punish on average less than, and get punished more than, any of the other team members.

Figure 8: Average expenditures of ranked team members in 4:4P (in points)

(boxed: active/passive punishment, measured in tokens and points respectively)

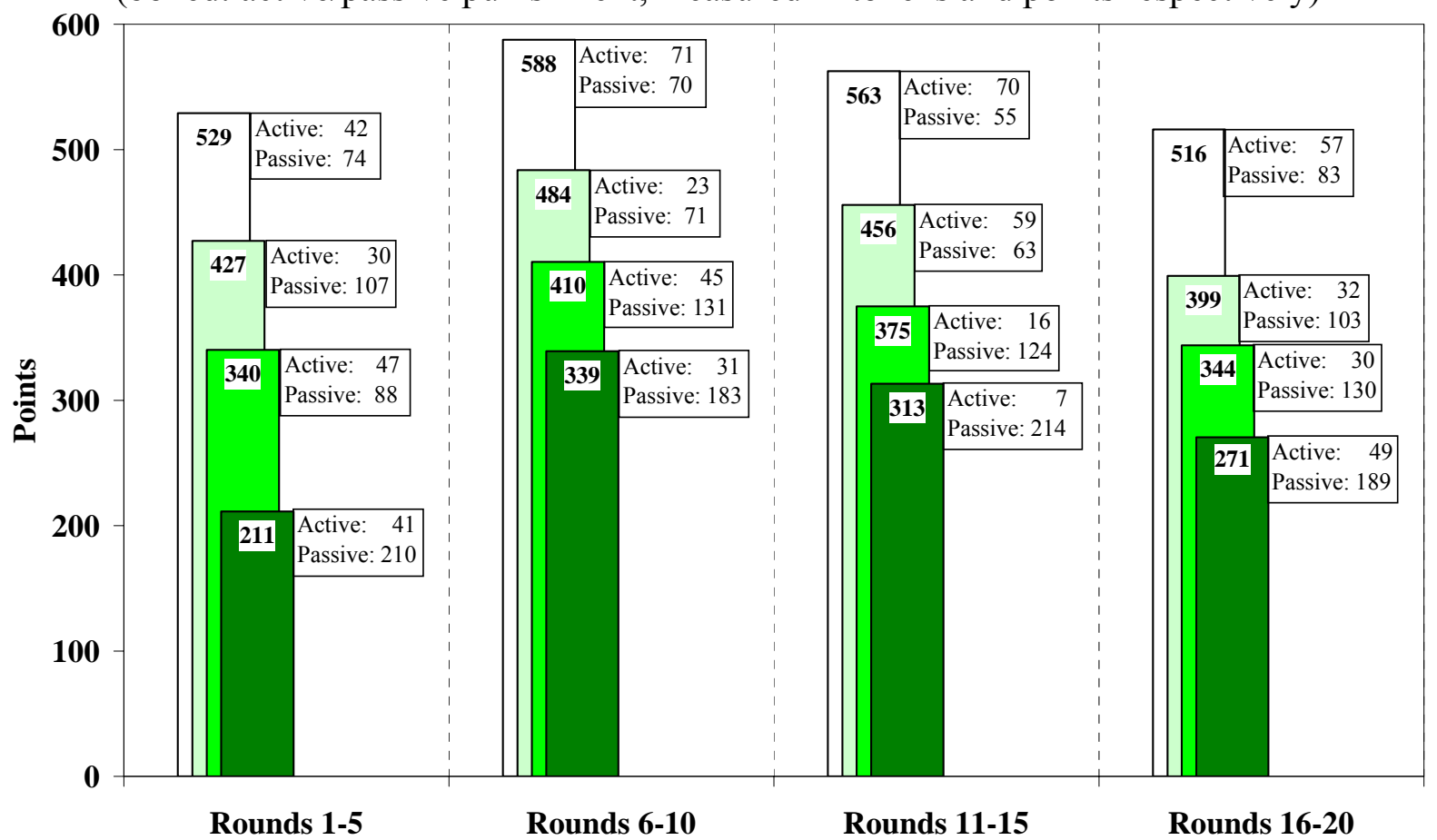

\section{Concluding remarks}

The results of our experiments show that group contests with punishment opportunities can be extremely destructive. Contests between groups that rely solely on their members' voluntary contributions to the collective effort are already characterised by investments in fighting far above equilibrium, but it is the addition of punishment possibilities that drives contest expenditure levels at the end of the experiments to about six times the equilibrium levels. Taking into account the resources spent on punishment itself the level of material losses is $869 \%$ that of the equilibrium level.

The data we present show one of the dark sides of within-group punishment. They may come as a surprise given the well-known results on the efficiency-enhancing effects of punishment in public goods games (Fehr and Gächter, 2000). In a conflict situation the possibility of punishing others compounds the problem that putting people into rivalling groups makes them more competitive, even though that leads to large material losses for all involved. The strength of our results suggests that powerful motives are behind the observed behaviour.

Some of the features of the process of punishment are quite similar to those found in public goods experiments. The more a person's investment in conflict deviates downwards from the team average the more that person gets punished. Those who punish more strongly are those whose investment deviates more strongly upwards from the group average. It appears that fear 
of being punished has a disciplining effect on team members and leads to the very wasteful investment levels. On average, total expenditure borne for conflict even exceeds the prize that can be expected to be won in the contest. So, while some behavioural patterns are similar to those observed in previous public goods experiments, the consequences are in stark contrast to them.

Experiments such as ours may help understand the large losses often observed in sociopolitical conflict. When human groups are immersed in situations of rivalry emotional forces may take over and lead to materially very inefficient outcomes. We find these outcomes in the abstract, anonymous environment of a laboratory experiment, in absence of any ethnic, religious or class division between the groups. Emotional forces related to rivalry between conflict parties can be conjectured to be much more intense in field environments involving parties that may have been in conflict for a long time.

This is the first experiment on team rent-seeking and naturally it raises as many questions as it can answer. One such question is how players deal with the two-dimensional nature of the strategic interaction in collective rent-seeking contests, where individuals interact within a team and at the same time the teams themselves compete against each other. Our subjects seem to focus more on the interaction with other team members than on that with the rival team but at this point one can only speculate whether this can be generalised and how this is best explained. Customised future experiments may examine this phenomenon more rigorously.

Our experimental setup was designed to explore the general nature of human behaviour in the face of a conflict situation. Beyond fundamental behavioural research we believe that the team rent-seeking paradigm is a suitable tool to analyse empirical questions about the causes of conflict, as a complement to field studies or as a substitute where field data are unavailable. Numerous studies have empirically investigated the impact of economic growth (Miguel, Satyanath, and Sergenti, 2004), or ethnic polarisation and fragmentation (Fearon and Laitin, 2003; Montalvo and Reynal-Querol, 2005) on likelihood and intensity of civil conflict. In the field robust data are notoriously hard to come by, since outbreaks of conflicts are infrequent events happening under many idiosyncratic circumstances. In the laboratory we can re-create a controlled set of conditions and incentives where we can analyse which factors of the economic and political environment are most likely to lead to conflict, keeping all other circumstances equal. The team rent-seeking paradigm seems a natural starting point for such empirical research, since it captures essential features of a conflict situation but is yet simple enough to implement, and its main components straightforward to manipulate. 


\section{References}

Abadie, A., and J. Gardeazabal (2003), "The Economic Costs of Conflict: A Case Study of the Basque Country," American Economic Review, 93, 113-132.

Andreoni, J., and J.H. Miller (2002), "Giving According to GARP: An Experimental Test of the Consistency of Preferences for Altruism," Econometrica, 70, 737-753.

Bornstein, G., and M. Ben-Yossef (1994), "Cooperation in inter-group and single-group social dilemmas," Journal of Experimental Social Psychology, 30, 52-67.

Davis, D., and R. Reilly (1998), "Do Too Many Cooks Spoil the Stew? An Experimental Analysis of Rent-seeking and the Role of a Strategic Buyer," Public Choice, 95, 89-115.

Denant-Boemont, L., D. Masclet, and C. Noussair (2007), "Punishment, Counterpunishment and Sanction Enforcement in a Social Dilemma Experiment," Economic Theory, 33, 145167.

Falk, A., E. Fehr and U. Fischbacher (2005), "Driving Forces behind Informal Sanctions," Econometrica, 73, 2017-2030.

Fearon, J., and D. Laitin (2003), "Ethnicity, Insurgency and Civil War," American Political Science Review, 97, 75-90.

Fehr E., G. Kirchsteiger und A. Riedl (1998), "Gift Exchange and Reciprocity in Competitive Experimental Markets," European Economic Review, 42, 1-34.

Fehr E., G. Kirchsteiger, A. Riedl (1993) "Does Fairness Prevent Market Clearing? An Experimental Investigation”, The Quarterly Journal of Economics ,108, 437.

Fehr, E., and S. Gächter (2000), "Cooperation and Punishment in Public Goods Experiments," American Economic Review, 90, 980-994.

Fuentes, J.A. (2005), "Violent Conflict and Human Development in Latin America: The Cases of Colombia, El Salvador and Guatemala," Human Development Report 2005, Human Development Report Office, Occasional Paper.

Garfinkel, M.R., and S. Skaperdas (2006), "Economics of Conflict: An Overview", in: T. Sandler and K. Hartley (eds.), Handbook of Defence Economics, Vol. 2, Chapter 4.

Guidolin, M., and E. La Ferrara (2005), "The Economic Effects of Violent Conflict: Evidence from Asset Market Reactions," Working Paper 2005-066A, Federal Reserve Bank of St. Louis.

Hazlett, T.W., and R.J. Michaels (1993), "The Cost of Rent-Seeking: Evidence from Cellular Telephone Lcense Lotteries," Southern Economic Journal, 59, 425-435.

Herrmann B. and H. Orzen (2007), "The appearance of homo rivalis: Social preferences and the nature of rent-seeking," Working paper in preparation, University of Nottingham.

Isaac, M., and S. Reynolds (1988), “Appropriability and Market Structure in a Stochastic Invention Model," The Quarterly Journal of Economics, 103(4), 647-672.

Konrad, K.A. (2007), “Strategy in Contests - An Introduction,” WZB Working Paper, SP II 200701.

Masclet, D., C. Noussair, S. Tucker, and M.-C. Villeval (2003), "Monetary and NonMonetary Punishment in the Voluntary Contributions Mechanism," American Economic Review, 93, 366-380. 
Miguel, E., S. Satyanath and E. Sergenti (2004), "Economic Shocks and Civil Conflict: An Instrumental Variables Approach,” Journal of Political Economy, 112, 725-753.

Millner, E.L., and M.D. Pratt (1989), "An Experimental Investigation of Efficient RentSeeking," Public Choice, 62, 139-151.

Millner E.L., and M.D. Pratt (1991), "Risk Aversion and Rent Seeking: An Extension and Some Experimental Evidence," Public Choice, 69, 81-92.

Montalvo, J.G., and M. Reynal-Querol (2005): "Ethnic Polarization, Potential Conflict, and Civil Wars," American Economic Review, 95(3), 796-816.

Nikiforakis N. (2004), "Punishment and Counter-punishment in Public Goods Games: Can We Still Govern Ourselves?,” Working Paper, Royal Holloway College London.

Olson, M. (1965), The Logic of Collective Action: Public goods and the theory of groups, Harvard University Press.

Öncüler, A., and R. Croson (2005), "Rent-Seeking for a Risky Rent: A Model of Experimental Investigation," Journal of Theoretical Politics, 17, 403-429.

Parco, J.E., A. Rapoport, and W. Amaldoss (2005), "Two-stage contests with budget constraints: An experimental study," Journal of Mathematical Psychology, 49, 320-338.

Potters J, C.G. de Vries, and F. van Winden (1998), "An Experimental Examination of Rational Rent-seeking," European Journal of Political Economy, 14, 783-800.

Robinson, I. (1995), "The East Timor Conflict (1975-)," in: M. Cranna and Nils Bhinda (eds.), The True Cost of Conflict. Seven Recent Wars and Their Effects on Society, New York: The New Press, 1-24.

Schmidt, D., R. Shupp, and J. Walker (2006), "Resource Allocation Contests: Experimental Evidence," CAEPR Working Paper 2006-004, Indiana University.

Sefton, M., R. Shupp and J. Walker (2007), "The Effect of Rewards and Sanctions in Provision of Public Goods," Economic Inquiry, 45(4), 671-690.

Shogren, J.F., and K.H. Baik (1991), "Reexamining Efficient Rent Seeking in Laboratory Markets," Public Choice, 69, 69-97.

Tullock, G. (1967), "The Welfare Costs of Tariffs, Monopolies and Thefts," Western Economic Journal, 5, 224-232.

Tullock, G. (1980), "Efficient rent-seeking," in: J. Buchanan, R. Tollison, and G. Tullock (eds.), Towards a Theory of the Rent-Seeking Society, College Station, Texas A\&M University Press, 97-112. 


\section{Appendix}

The following is a copy of the instructions for the 4:4P treatment. The instructions for the other treatments are straightforward variations of these.

\section{Instructions}

Welcome! You are about to take part in an experiment in the economics of decision making. You will be paid in private and in cash at the end of the experiment. The amount you earn will depend on your decisions, so please follow the instructions carefully.

During the experiment you will have the chance to earn points, which will be converted into cash at the end of today's session, using an exchange rate of 30 points $=1 \mathrm{p}$. Thus, the more points you earn, the more cash you will receive at the end of the session. You will start with an endowment of 3000 points.

\section{It is important that you do not talk to any of the other participants until the session is over.}

At the beginning of the experiment you will be matched with three other people, randomly selected from the people in this room, to form up a team of four. In total there will be four teams (each consisting of four people). During the experiment your team will be playing against one of the other teams and that team will be the opponent of your team. Note that you will not learn who your team colleagues or your opponents are, neither during nor after today's session. Likewise, neither your team colleagues nor your opponents will learn about your identity.

The experiment will consist of 20 rounds, and in each round your team and your opponents will be competing for a prize, as will now be explained.

At the beginning of each round you will receive 1000 points from us. You can then use these points to purchase "contest tokens" for your team. Each contest token you buy costs you 1 point and you can purchase up to 1000 of these tokens. Any points you do not invest into contest tokens will simply be added to your point balance and are yours to keep. Likewise, your team colleagues and your opponents will have the chance to buy contest tokens, in exactly the same way.

As soon as everybody has chosen how many contest tokens to buy, a lottery wheel will determine whether your team or your opponents win the prize. The prize is worth 4000 points (1000 for each team member), and your chances of winning the prize depend on how many contest tokens your team has bought and how many contest tokens your opponents have bought. This works as follows:

The lottery wheel is divided into two shares with different colours. One share belongs to your team and the other share belongs to your opponents. The size of your share and the size of your opponents' share on the lottery wheel are exact representations of the number of contest tokens bought by your team and bought by your opponents. For instance, if your team and your opponents have each bought the same number of contest tokens, each team gets a $50 \%$ share of the lottery wheel. If your team has bought twice as many contest tokens as your opponents have, your team gets two thirds of the wheel and your opponents get one third of the wheel.

Once the shares of the lottery wheel have been determined, the wheel will start to rotate and after a short while it will stop at random. Just above the lottery wheel there is an indicator at 
the 12 o'clock position. If the wheel comes to a halt such that the indicator points at your team's share your team wins. If the wheel comes to a halt such that the indicator points at your opponents' share, the opponent team takes the prize and your team will have lost.

Thus, your chances of winning the prize increase with the number of contest tokens your team buys. Conversely, the more contest tokens your opponents buy, the higher the probability that you lose. If one of the teams doesn't buy any contest tokens, the other team wins the prize with certainty. If nobody buys any contest tokens, no lottery takes place and the prize is lost.

At the end of each round, after the lottery is resolved and the winning team is determined, team members can, if they wish, assign "deduction tokens" to each other (not to members of the other team). Each deduction token you receive from a team colleague will reduce your point balance by 3 points. It is possible that this wipes out your earnings from a particular round. (Theoretically, the reduction could even exceed your earnings from the round, but the computer will disregard such "excess" reduction.)

Every deduction token you assign to a team colleague will cost you 1 point (and will reduce the recipient's point balance by 3 points). The maximum total number of deduction tokens you can assign to your team colleagues is 500 . If you do not wish to assign deduction tokens to a person, simply fill in a " 0 ".

The points you earn in each round will be added together. At the end of the session you will be paid based on your total point earning from all 20 periods. 